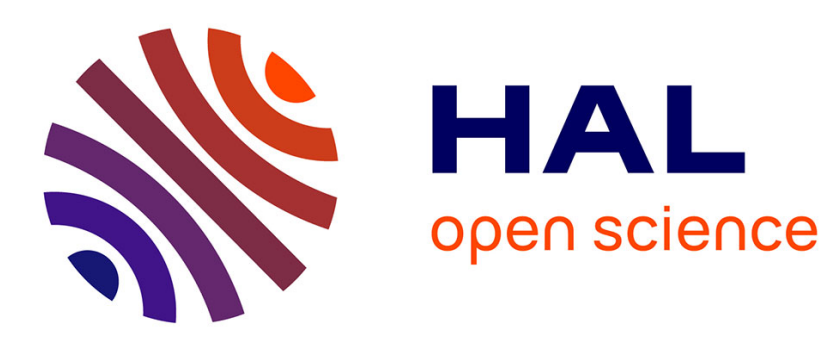

\title{
Symbiotic equilibrium between Sodium Fast Reactors and Pressurized Water Reactors supplied with MOX fuel Guillaume Martin, C. Coquelet-Pascal
}

\section{To cite this version:}

Guillaume Martin, C. Coquelet-Pascal. Symbiotic equilibrium between Sodium Fast Reactors and Pressurized Water Reactors supplied with MOX fuel. Annals of Nuclear Energy, 2017, 103, pp.356 362. 10.1016/j.anucene.2017.01.041 . cea-01908263

\section{HAL Id: cea-01908263 https://hal-cea.archives-ouvertes.fr/cea-01908263}

Submitted on 30 Oct 2018

HAL is a multi-disciplinary open access archive for the deposit and dissemination of scientific research documents, whether they are published or not. The documents may come from teaching and research institutions in France or abroad, or from public or private research centers.
L'archive ouverte pluridisciplinaire HAL, est destinée au dépôt et à la diffusion de documents scientifiques de niveau recherche, publiés ou non, émanant des établissements d'enseignement et de recherche français ou étrangers, des laboratoires publics ou privés. 


\title{
Symbiotic equilibrium between Sodium Fast Reactors and Pressurized Water Reactors supplied with MOX fuel
}

\author{
G. Martin $^{\mathrm{a}, *}$, C. Coquelet-Pascal ${ }^{\mathrm{b}}$ \\ ${ }^{a}$ CEA - DEN/DER/SPRC/LECy, Bât. 230, 13108 Saint-Paul-Lez-Durance Cedex, France \\ ${ }^{\mathrm{b}}$ CEA - DEN/DER/SPRC/LEDC, Bât. 230, 13108 Saint-Paul-Lez-Durance Cedex, France
}

\section{A R T I C L E I N F O}

\section{Article history:}

Received 14 September 2016

Received in revised form 25 January 2017

Accepted 28 January 2017

\section{Keywords:}

Nuclear energy

Plutonium

Fast reactors

SFR

Thermal reactors

Fuel reprocessing

Symbiotic nuclear systems

$\mathrm{EPR}^{\mathrm{TM}}$

\begin{abstract}
A B S T R A C T
The symbiotic equilibrium between $1.51 \mathrm{GWe}$ breeder SFR (Sodium Fast Reactors) and 1.6 GWe EPR ${ }^{\mathrm{TM}}$ (European Pressurized water Reactors) is studied. $\mathrm{EPR}^{\mathrm{TM}}$ are only supplied with MOX (Mixed OXide) fuel to avoid the use of natural uranium. The equilibrium is studied by considering the flows of plutonium. Its isotopic composition is here described by a single real number referred to as the Pu grade. Plutonium flows through both reactor types are characterized by using linear functions of the Pu grade in new fuels. These functions have been determined by fitting data from a former scenario study carried out with the COSI6 simulation software.

Two different reprocessing strategies are considered. With joint reprocessing of all spent fuels, total and fissile plutonium flows balance for a unique fraction $x$ of $\mathrm{EPR}^{\mathrm{TM}}$ in the fleet, equal to 0.2547 . This $x$ value is consistent with the results reported in the former scenario study mentioned above. When $\mathrm{EPR}^{\mathrm{TM}}$ spent fuels are used in priority to supply SFR (distinct reprocessing), $x$ reaches 0.2582 at most. COSI6 simulations have been performed to further assess these results. The EPR ${ }^{\mathrm{TM}}$ fraction in the fleet at symbiotic equilibrium barely depends on the applied reprocessing strategy, so that the more flexible joint reprocessing constitutes the reference option in that case.
\end{abstract}

(c) 2017 Elsevier Ltd. All rights reserved.

\section{Introduction}

Closing the fuel cycle is a major challenge to improve the sustainability of civil nuclear power, and complex systems have been studied in this respect (see e.g. Gao and Ko, 2014; Lindley et al., 2014). In this context, a symbiotic nuclear system denotes a fleet composed of various reactor types: reactors which produce fissile elements compensate for their consumption (Chersola et al., 2015). Here, the main fissile element is plutonium, produced in breeder SFR (Sodium Fast Reactors) and consumed in EPR ${ }^{\mathrm{TM}}$ (European Pressurized water Reactors) only supplied with MOX (Mixed OXide $(\mathrm{U}, \mathrm{Pu}) \mathrm{O}_{2}$ ) fuel. Indeed, a fleet composed of SFR and $\mathrm{EPR}^{\mathrm{TM}}$ can dispense with natural resources as long as some depleted or reprocessed uranium is available to supplement $\mathrm{Pu}$ in new fuels.

A recent article (Martin et al., 2016) reported scenarios of the French fleet evolving towards a nuclear system including both these reactor types exclusively. The mixed fleet at the end of the scenarios was composed of circa a quarter of $\mathrm{EPR}^{\mathrm{TM}}$, so that the total plutonium inventory was nearly steady, which indicates a fleet composition close to a symbiotic equilibrium when all irradiated fuels are reprocessed. Joint reprocessing of all spent fuels was

\footnotetext{
* Corresponding author.

E-mail address: guillaume.martin@cea.fr (G. Martin).
}

applied to improve the fuel management flexibility. Another viable strategy would have consisted in recycling the Pu from SFR spent fuels in EPR ${ }^{\mathrm{TM}}$ in priority (distinct reprocessing). These two reprocessing strategies are presented in Fig. 1.

The aim of the present study is to assess the conditions under which a symbiotic equilibrium exists for each reprocessing strategy. The basic equations which drive the symbiotic equilibrium for a joint reprocessing of spent fuels are set up. They are solved by considering only the flows of plutonium, whose isotopic composition is described by a single number referring to its grade. The way plutonium evolves under irradiation has been deduced from data collected from the previous scenario study mentioned above (Martin et al., 2016). The joint reprocessing strategy leads to a unique fleet composition at symbiotic equilibrium.

The symbiotic equilibrium between EPR ${ }^{\mathrm{TM}}$ and SFR applying distinct reprocessing of spent fuels is then described. Several symbiotic equilibriums are found. The fraction of $\mathrm{EPR}^{\mathrm{TM}}$ in the fleet is maximal when all the plutonium introduced in EPR ${ }^{\mathrm{TM}}$ MOX fuels comes from SFR spent fuels. Nevertheless the gain with respect to joint reprocessing appears marginal, which means that fissile plutonium savings associated to this complex reprocessing strategy remain quite low. In this context, joint reprocessing no doubt constitutes the reference option for such a symbiotic nuclear system. 
(a)

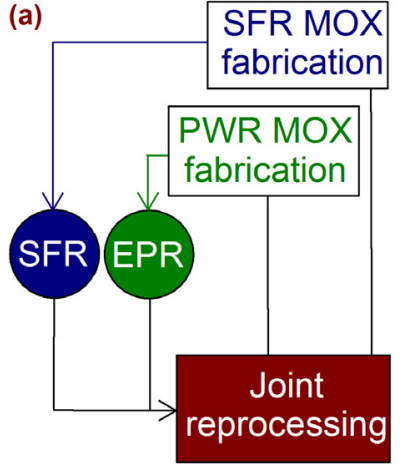

(b)

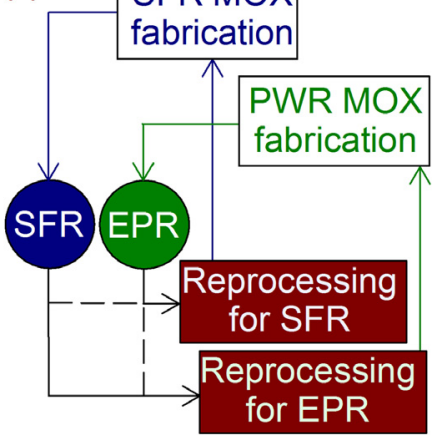

Fig. 1. Joint reprocessing (a) and distinct reprocessing (b) of $\mathrm{EPR}^{\mathrm{TM}}$ and $\mathrm{SFR}$ spent fuels.

\section{Previous work}

Mixed nuclear fleets composed of EPR ${ }^{\mathrm{TM}}$ and SFR were previously simulated (Martin et al., 2016) using the COSI6 scenario software (Coquelet-Pascal et al., 2015), developed by CEA. COSI6 can simulate in detail the time evolution of a nuclear reactor fleet with its associated fuel cycle facilities. New fuel compositions can be estimated by applying equivalence models. COSI6 was here coupled with the CESAR5.3 code (Vidal et al., 2012) to calculate the composition evolution of matters in pile or in storage conditions. CESAR5.3 solves the Bateman equation for 109 heavy nuclides and more than 200 fission products using JEFF3.1.1 nuclear data and one-group cross-section libraries for reactor modeling.

Two simulations of the French fleet evolving step by step (Chabert et al., 2015) towards a symbiotic nuclear system were run (Martin et al., 2016). They were built within the limits of conservative criteria defined in concert with French industrialists (AREVA and EDF), so that they are realistic as regards our current knowledge and feedback (Martin et al., 2016). Electricity production curves of both scenarios are shown in Fig. 2.

In these scenarios, EPR ${ }^{\mathrm{TM}}$ and SFR operate in diverse conditions over several decades. In this respect all fuel batches passing through breeder SFR (1076 batches) and EPR ${ }^{\mathrm{TM}}$ only fueled with MOX (321 batches) during the progressive scenario (see Fig. 2.a) provide a consistent reference dataset for describing the fuel evolution in pile (see Section 3.2). The cores of these reactors are

respectively managed by thirds and fifths. Main characteristics of simulated $\mathrm{EPR}^{\mathrm{TM}}$ and SFR are reported in Table 1.

At the end of the simulations, mixed nuclear fleets were composed of $10 \mathrm{EPR}^{\mathrm{TM}}$ with 28 or 30 SFR. If the real number $x$ stands for the fraction of $\mathrm{EPR}^{\mathrm{TM}}$ in the fleet, simulations were carried out at $x=0.2632$ and $x=0.25$. These fleet compositions led to rather stable plutonium inventories, but even so not strictly constant as shown in Fig. 3. A slight increase of the plutonium stock counts for too much breeder SFR in the fleet $(x=0.25)$, whereas a decrease counts for the opposite $(x=0.2632)$. Therefore one may expect that the EPR ${ }^{\mathrm{TM}}$ fraction in the fleet which perfectly satisfies the symbiotic equilibrium is comprised between these two values.

Table 1

Description of 1.51 GWe breeder SFR and of $\mathrm{EPR}^{\mathrm{TM}}$ fueled with MOX only.

\begin{tabular}{lll}
\hline & \multicolumn{2}{l}{ Reactors } \\
\cline { 2 - 3 } & EPR $^{\mathrm{TM}}$ 100\% MOX & Breeder SFR CFV V1 \\
\hline Power (GWe) & 1.60 & 1.51 \\
Net yield (\%) & 35.6 & 40.3 \\
Core mass (tHM) & 125 & 129 \\
Core composition & MOX only & $40 \%$ fissile $60 \%$ fertile \\
Fuel need (tHM/yr) & MOX: 25.4 & fissile: 8.1 fertile: 8.7 \\
Fissile fuel BU & 53.5 GWd/t & $116.3 \mathrm{GWd} / \mathrm{t}$ \\
\hline
\end{tabular}

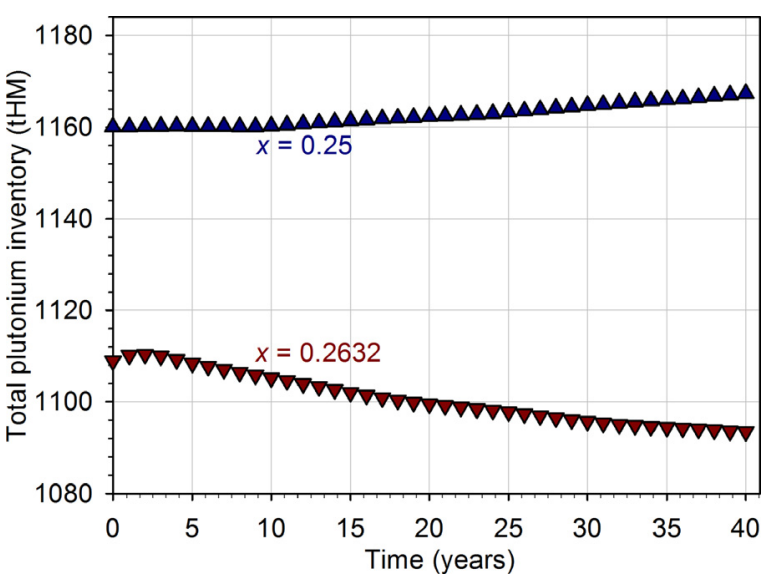

Fig. 3. Evolution over 40 years of the total plutonium inventory associated to two mixed EPR ${ }^{\mathrm{TM}}$ - SFR fleets (Martin et al., 2016), $x$ being the $\mathrm{EPR}^{\mathrm{TM}}$ fraction.
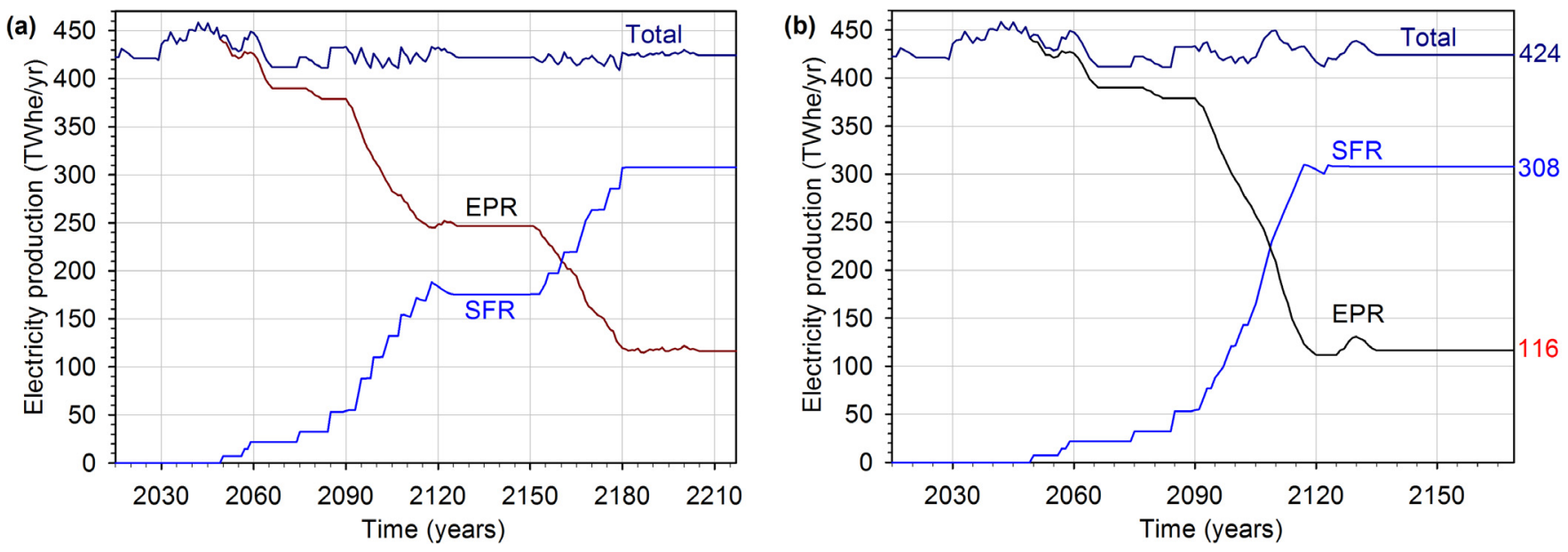

Fig. 2. Electricity production of $\mathrm{EPR}^{\mathrm{TM}}$ and SFR during the progressive (a) and fast (b) transition scenarios to a symbiotic nuclear fleet (Martin et al., 2016). 


\section{Joint reprocessing}

\subsection{Description}

Joint reprocessing of all spent fuels has first been considered. As in similar scenario studies (Martin and Girieud, 2016), a minimal cooling time of 5 years occurs between spent fuel unloading and reprocessing operations. Reprocessing essentially consists in extracting from spent fuels the plutonium which enters into MOX fuel fabrication (for EPR ${ }^{\mathrm{TM}}$ and SFR). Then, at least two additional years elapse before a new MOX fuel can be loaded in reactor. The minimal time during which the plutonium decays before its recycling in pile is therefore of 7 years. The fuel cycle with joint reprocessing is illustrated in Fig. 4.

In Fig. 4 are reported the parameters which describe the plutonium flows in the closed fuel cycle. $N_{E}$ and $N_{S}$ represent the Pu consumptions of EPR ${ }^{\mathrm{TM}}$ and SFR respectively, whereas $P_{E}$ and $P_{S}$ stand for $\mathrm{Pu}$ productions. Joint reprocessing results in the same plutonium isotopic vector in all new fuels: $G$ denotes its grade at symbiotic equilibrium. In a general case, one can note that $\mathrm{Pu}$ grades should be defined as isotopic vectors whose size is the number of $\mathrm{Pu}$ isotopes present in irradiated fuels. Here however, the Pu grade has been reduced to a single real number according to the weight ratio (2) (see Section 3.2). This way to proceed is further discussed in Section 5. Table 2 reports all parameters used along this article, some of them referring to the distinct fuel reprocessing strategy described in Section 4.

All the isotopes present in the fuels in pile contribute to neutron capture and/or thermalization processes, and participate in the core neutron behavior. Here however, only plutonium isotopes are assumed in first order to impact the fuel flows drawn in Fig. 4. It is then possible to write the conditions of the symbiotic

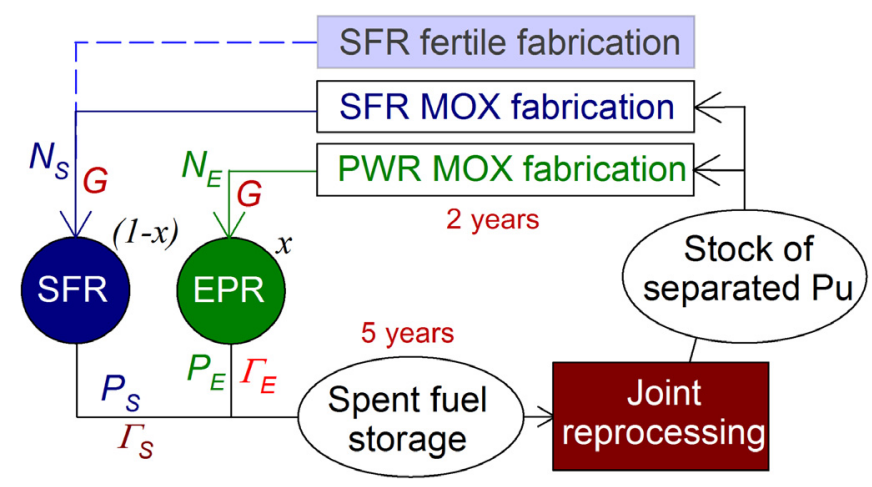

Fig. 4. Fuel cycle of a mixed $\mathrm{EPR}^{\mathrm{TM}}$ - SFR fleet with joint reprocessing of spent fuels.

Table 2

Symbol table.

\begin{tabular}{lll}
\hline Parameters & Unit & Description \\
\hline$x$ & $\in[0,1]$ & EPR $^{\mathrm{TM}}$ fraction in the fleet \\
$N_{E}$ & $\mathrm{tHM} / \mathrm{yr}$ & Pu consumption in an $\mathrm{EPR}^{\mathrm{TM}}$ reactor \\
$N_{S}$ & $\mathrm{tHM} / \mathrm{yr}$ & Pu consumption in a SFR reactor \\
$P_{E}$ & $\mathrm{tHM} / \mathrm{yr}$ & Pu output from an EPR \\
$P_{S}$ & $\mathrm{tHM} / \mathrm{yr}$ & Pu output from a SFR reactor \\
$\Gamma_{E}$ & $\in[0,1]$ & Pu grade in $\mathrm{EPR}^{\mathrm{TM}}$ spent fuel \\
$\Gamma_{S}$ & $\in[0,1]$ & Pu grade in SFR spent fuel \\
$g$ & $\in[0,1]$ & Plutonium grade in new fuel \\
$G, G_{E}^{*}, G_{S}^{*}$ & $\in[0,1]$ & Equilibrium Pu grades \\
$\epsilon_{E}$ & $\in[0,1]$ & EPR $^{\mathrm{TM}}$ Pu fraction recycled into EPR \\
$\epsilon_{S}$ & $\in[0,1]$ & SFR Pu fraction recycled into SFR \\
\hline
\end{tabular}

equilibrium with joint reprocessing as a system of two equations (see system (1)).

$$
\left\{\begin{array}{l}
x N_{E}(G)+(1-x) N_{S}(G)=x P_{E}(G)+(1-x) P_{S}(G) \\
G=\frac{(1-x) P_{S}(G) \Gamma_{S}(G)+x P_{E}(G) \Gamma_{E}(G)}{(1-x) P_{S}(G)+x P_{E}(G)}
\end{array}\right.
$$

The first equation is here a balance between plutonium production and consumption. Pu need and production functions depend here upon the plutonium grade $\mathrm{G}$. Only two $\mathrm{Pu}$ isotopes contribute significantly to fissions inside the reactor core, namely ${ }^{239} \mathrm{Pu}$ and ${ }^{241} \mathrm{Pu}$. The second equation in system (1) provides that, with joint reprocessing, the plutonium grade $G$ in new fuels is a weighted average of plutonium grades in irradiated fuels unloaded from both reactor types ( $\Gamma_{E}$ and $\Gamma_{S}$ for $\mathrm{EPR}^{\mathrm{TM}}$ and SFR respectively). The balance of fissile $\mathrm{Pu}$ isotopes can be deduced by multiplying both equations in system (2).

\subsection{Assumptions}

The plutonium grade is here described by a single real number. The Pu grade does not include ${ }^{241} \mathrm{Am}$ (Martin et al., 2016) which derives from ${ }^{241} \mathrm{Pu}$ and acts as a neutron absorber. This element is usually accounted for since its concentration increases as $\mathrm{Pu}$ ages. However, in the steady-state fleet, the time interval between spent fuel unloading and the reloading in pile of the Pu that it contains should ideally not vary: the fastest possible recycling (7 years) applies since it constitutes the best option in terms of plutonium management. Steady $\mathrm{Pu}$ aging explains why the $\mathrm{Pu}$ grade can be defined without ${ }^{241} \mathrm{Am}$, according to relation (2).

$g=\frac{{ }^{239} \mathrm{Pu}+{ }^{241} \mathrm{Pu}}{\sum_{M=236}^{M=244} \mathrm{Pu}}$

Plutonium need, production and output grade functions here characterize each reactor present in the mixed fleet: $E R^{\mathrm{TM}}$ and SFR. These three functions for both reactor types depend on the plutonium grade in new fuels. They are presented in Fig. 5 (6 graphs). Fuel batches from the progressive transition scenario previously simulated (Martin et al., 2016) (see Section 2) have been used to calculate them: these data appear as dots in Fig. 5.

All the reactor functions have here been defined as linear functions of the plutonium grade in new fuels (see Fig. 5). This has been partly inferred from the equivalence model for SFR (Baker and Ross, 1963) which linearly depends on each Pu isotope concentration, although this particular aspect of the simulations may be improved (Krivtchik, 2014). For the period between spent fuel unloading and the reloading of the Pu that it contains, only the decay of fissile ${ }^{241} \mathrm{Pu}$, of half-life of 14.4 years, should significantly impact the symbiotic equilibrium. A 7-year decay of ${ }^{241} \mathrm{Pu}$ has therefore been applied to fuel batches which were just irradiated to account for intermediate cooling, reprocessing and fuel fabrication steps: this decay is accounted for in Fig. 5.b, c, e and f. Pu losses during spent fuel reprocessing are neglected.

The fuels after irradiation in SFR show a large variety of plutonium contents and grades. Whereas high-grade Pu has been kept for $\mathrm{EPR}^{\mathrm{TM}}$ MOX fuel fabrication since its $\mathrm{Pu}$ content should not exceed a limit for safety reasons (Martin et al., 2016), the SFR CFV core has a particularly large fuel acceptance (Buiron and Dujcikova, 2015). Spent fuels containing low-grade plutonium, namely enriched reprocessed uranium, PWR MOX and mostly aged fuels, therefore supplied SFR as far as possible (Martin et al., 2016). As a consequence of this, plutonium isotopic composition in new SFR fuels varied strongly, which explains the dispersion of the corresponding outcomes (Fig. 5.e and f). In particular, fuel batches with plutonium of similar grade $g$ but different aging led to markedly different results. 
Need
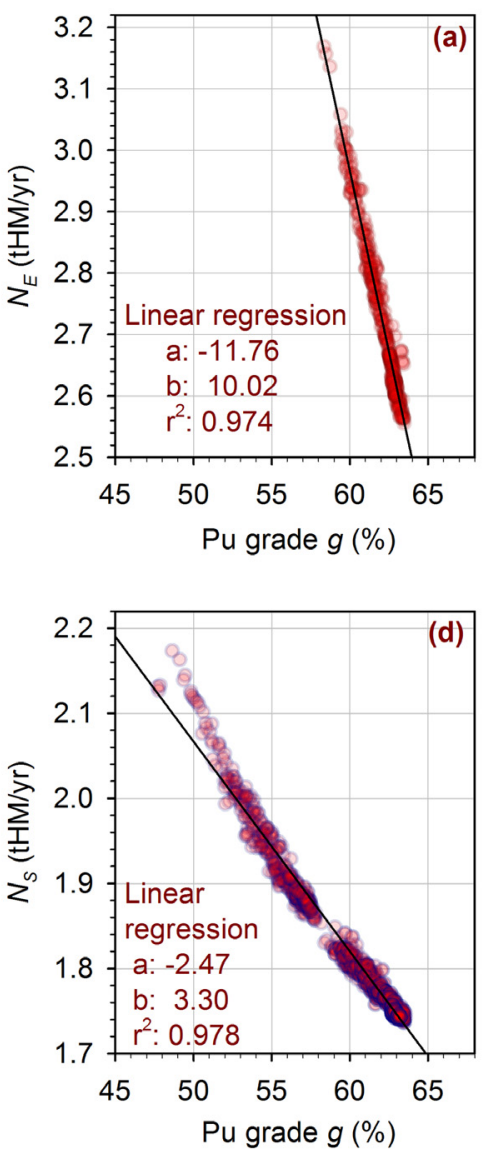

Production
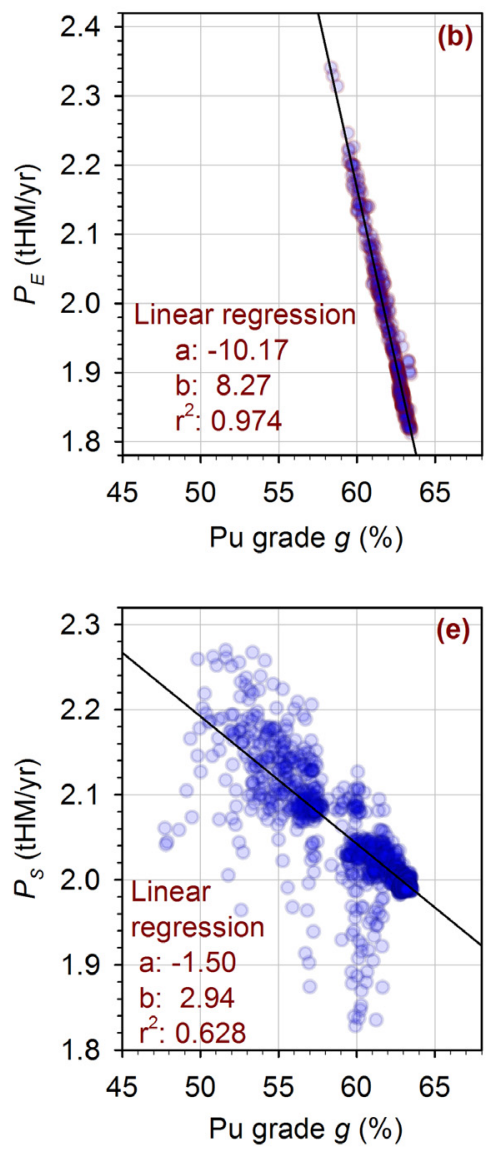

Output Pu grade
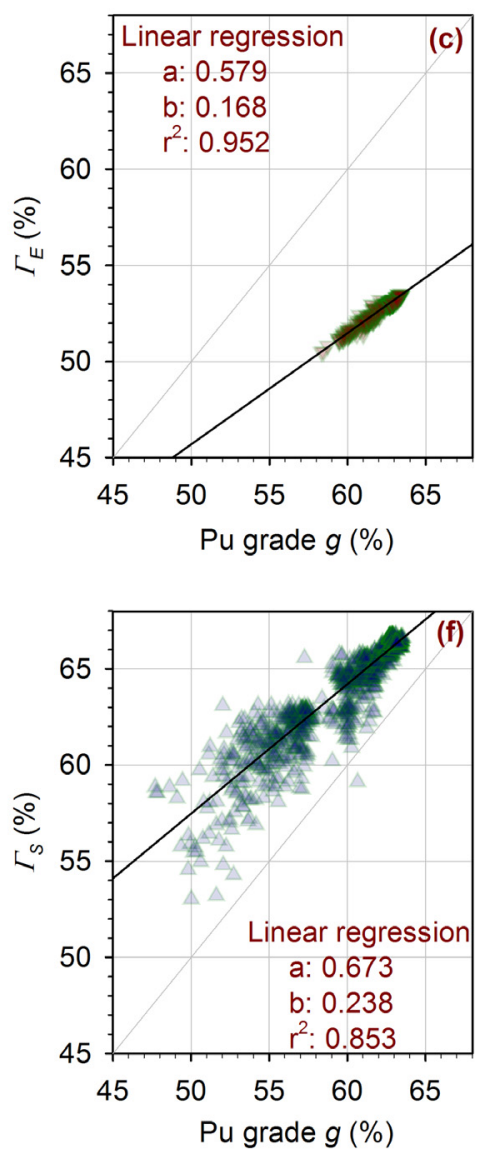

Fig. 5. Linear fits of the data relative to plutonium consumption, production and grade evolution (Martin et al., 2016) for both reactor types.

\subsection{Solution}

The system of Eqs. (1) is solved in this section. The 2 unknowns are the fleet composition (EPR ${ }^{\mathrm{TM}}$ fraction $x$ ) and the $\mathrm{Pu}$ grade in fresh MOX fuels $G$ at symbiotic equilibrium. The first equation in this system stands for the balance between total plutonium production and consumption. It leads to a collection of fleet composi-

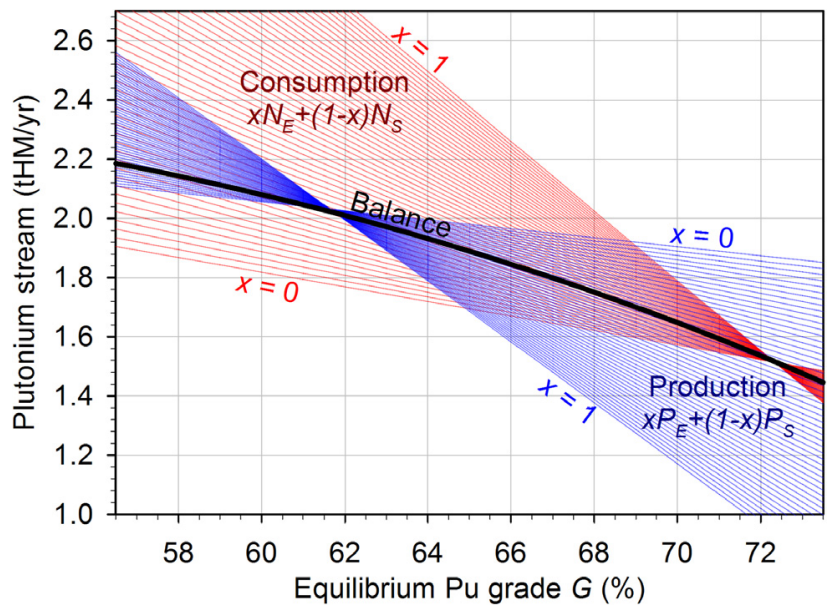

Fig. 6. Balance between Pu production (blue lines) and consumption (red lines) applying joint reprocessing of spent fuels. (For interpretation of the references to color in this figure legend, the reader is referred to the web version of this article.) tions ( $x$ values) as a function of the plutonium grade $G$ at equilibrium, as shown in Fig. 6.

The second equation in system (1) can also be reduced to a relation between $x$ and $G$. The system is therefore solved by intersecting two functions $x(G)$, inferred from both equations in system (1) (see Fig. 7). The mixed nuclear system of EPR ${ }^{\mathrm{TM}}$ and SFR with joint reprocessing is symbiotic for a unique fleet composition, corre-

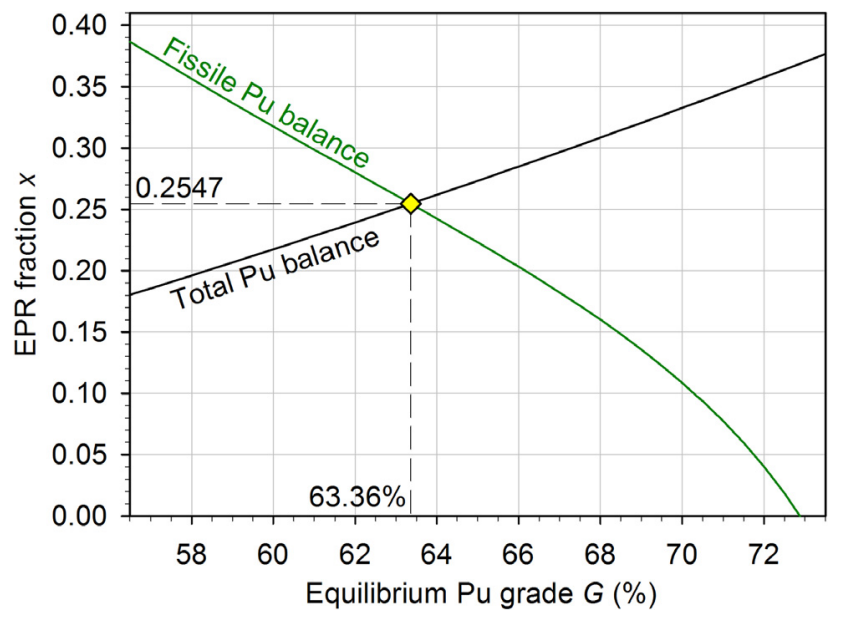

Fig. 7. Symbiotic equilibrium with joint reprocessing. 
sponding here to a fraction of EPR ${ }^{\mathrm{TM}}$ of 0.2547 . As expected, this fraction is included between 0.25 and 0.2632 (see Section 2).

\section{Distinct reprocessing}

\subsection{Description}

Mean production on consumption ratios in breeder SFR have been calculated for total and fissile plutonium: lines reported in Fig. 8 have been deduced from the linear regression functions shown in Fig. 5. The dots are derived from the results of the previous COSI6 simulation (Martin et al., 2016) (progressive transition scenario). The considered breeder SFR core concept is usually supposed to have a breeding ratio around 1.2 (Tiphine et al., 2015), which actually corresponds here to the minimum of the average profit in fissile $\mathrm{Pu}$ after irradiation.

The green curve in Fig. 8 has been tabulated from the regression lines in Fig. 5.d, e and $\mathrm{f}$ (applying $P_{S} \Gamma_{S} / N_{S} g$ ). It reveals that the fissile Pu production in SFR is higher on average when the plutonium grade in fresh fuels decreases below $60 \%$. Since plutonium grade from unloaded EPR ${ }^{\mathrm{TM}}$ fuels is inferior to $55 \%$ after 7 years of cooling, as shown in Fig. 5.c, a way to increase the fissile Pu production in the mixed nuclear system would therefore consist in loading the low grade $\mathrm{Pu}$ from $\mathrm{EPR}^{\mathrm{TM}}$ spent fuels in SFR in priority. Distinct reprocessing of $\mathrm{EPR}^{\mathrm{TM}}$ and SFR spent fuels would be applied as illustrated in Fig. 9.

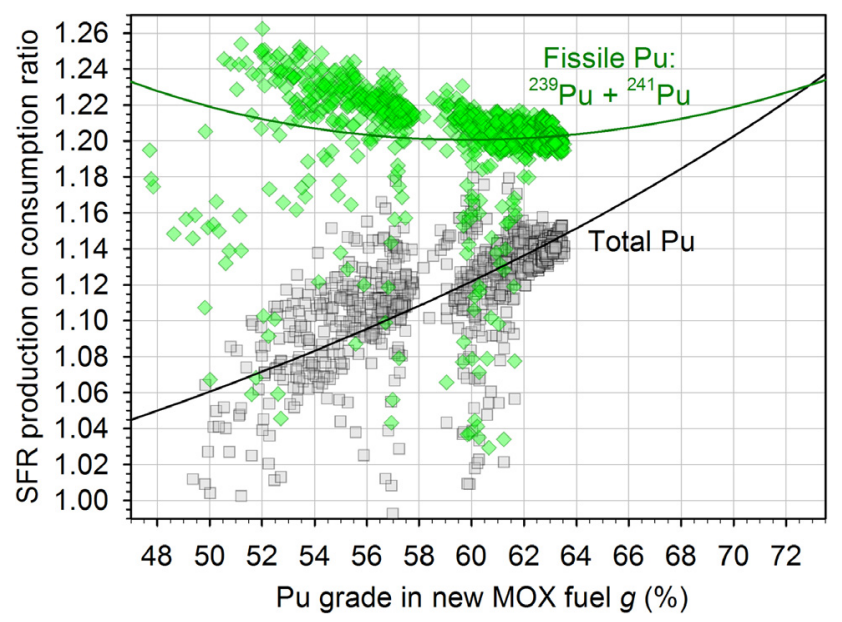

Fig. 8. Mean production on consumption ratios in a breeder SFR for total and fissile plutonium. The dots are derived from a previous study (Martin et al., 2016).

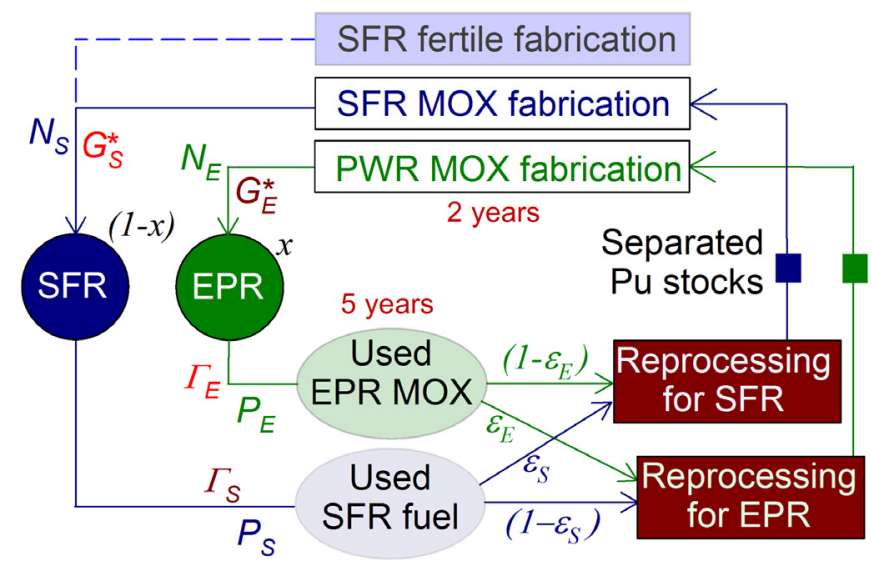

Fig. 9. Fuel cycle of a mixed fleet with distinct reprocessing of spent fuels.
Distinct reprocessing implies that the plutonium grades inside new EPR ${ }^{\mathrm{TM}}$ and SFR MOX fuels are different. They are respectively noted $G_{E}^{*}$ and $G_{S}^{*}$. Whereas most of EPR ${ }^{\mathrm{TM}}$ spent fuels supply SFR, plutonium whose grade has improved in SFR is mainly used to fabricate PWR MOX fuels. A fraction of the plutonium coming from SFR spent fuels may however be recycled into SFR at symbiotic equilibrium, in case there is not enough Pu in $\mathrm{EPR}^{\mathrm{TM}}$ spent fuels to feed them. In the same way a fraction of the Pu from EPR ${ }^{\mathrm{TM}}$ spent fuels might be recycled into EPR ${ }^{\mathrm{TM}}$. Let $\epsilon_{S}$ and $\epsilon_{E}$ be the spent fuel fractions self-recycled into SFR and EPR ${ }^{\mathrm{TM}}$ respectively. A system of four independent equations (see system (3)) can then be written to describe the symbiotic equilibrium in case of distinct reprocessing of spent fuels.

$$
\begin{aligned}
& x N_{E}\left(G_{E}^{*}\right)=(1-x)\left(1-\epsilon_{S}\right) P_{S}\left(G_{S}^{*}\right)+x \epsilon_{E} P_{E}\left(G_{E}^{*}\right) \\
& (1-x) N_{S}\left(G_{S}^{*}\right)=x\left(1-\epsilon_{E}\right) P_{E}\left(G_{E}^{*}\right)+(1-x) \epsilon_{S} P_{S}\left(G_{S}^{*}\right) \\
& G_{E}^{*}=\frac{(1-x)\left(1-\epsilon_{S}\right) P_{S}\left(G_{S}^{*}\right) \Gamma_{S}\left(G_{S}^{*}\right)+x \epsilon_{E} P_{E}\left(G_{E}^{*}\right) \Gamma_{E}\left(G_{E}^{*}\right)}{(1-x)\left(1-\epsilon_{S}\right) P_{S}\left(G_{S}^{*}\right)+x \epsilon_{E} P_{E}\left(G_{E}^{*}\right)} \\
& G_{S}^{*}=\frac{(1-x) \epsilon_{S} P_{S}\left(G_{S}^{*}\right) \Gamma_{S}\left(G_{S}^{*}\right)+x\left(1-\epsilon_{E}\right) P_{E}\left(G_{E}^{*}\right) \Gamma_{E}\left(G_{E}^{*}\right)}{(1-x) \epsilon_{S} P_{S}\left(G_{S}^{*}\right)+x\left(1-\epsilon_{E}\right) P_{E}\left(G_{E}^{*}\right)}
\end{aligned}
$$

The two first equations stand for total plutonium balances at equilibrium. By summing their left and right members, it comes the first equation in system (1), i.e. the equilibrium between plutonium flows just before reactor loading. The two last equations in system (3) are relative to plutonium grades, i.e. to the flows of fissile plutonium isotopes.

\subsection{Solution}

Under the same set of assumptions applied above (see Section 3.2), the non-linear system (3) returns to a minimization problem that has been solved numerically using a GRG algorithm (Lasdon and Waren, 1983). Convergence is reached when the $\chi^{2}$ indicator calculated according to the relation (4) goes down below $10^{-9}$, with $L_{i}$ and $R_{i}$ being the left and right members of the $\mathrm{i}^{\text {th }}$ equation in system (3).

$\chi^{2}=\sum_{i=1}^{i=4}\left(\frac{L_{i}-R_{i}}{L_{i}}\right)^{2}$

There are 5 degrees of freedom in system (3): $x, G_{S}^{*}, G_{E}^{*}, \epsilon_{S}$ and $\epsilon_{E}$. Since it includes only 4 equations, this system has been solved by setting one parameter. With $\epsilon_{E}=0$, a single set of values has been found at symbiotic equilibrium. Then increasing values of $\epsilon_{E}$ have been considered to solve the system and several EPR ${ }^{\mathrm{TM}}$ fractions $x$ at symbiotic equilibrium have been determined. They are reported in Fig. 10.

The highest $\mathrm{EPR}^{\mathrm{TM}}$ fraction $x$ is 0.2582 , found when no plutonium from $\mathrm{EPR}^{\mathrm{TM}}$ is recycled into $\mathrm{EPR}^{\mathrm{TM}}\left(\epsilon_{E}=0\right)$. As $\epsilon_{E}$ rises, $x$ decreases. When $\epsilon_{E}$ is near $33.6 \%$, the system converges to a solution for which $\epsilon_{E}+\epsilon_{S}=1$. This condition implies that the two last equations in system (3) are equivalent: it comes $G_{E}^{*}=G_{S}^{*}=G$, which returns to joint reprocessing of spent fuels. The solution found in Section 3.3 is confirmed $(x=0.2547)$. In Table 3 are detailed the solutions corresponding to $x=0.2582$ (highest $x$ value applying distinct reprocessing) and $x=0.2547$ (joint reprocessing).

The fractions of $\mathrm{EPR}^{\mathrm{TM}}$ in the fleet are barely distinct for both reprocessing strategies. This is all the more true since in practice, this difference should be generally less than one power plant in a real nuclear fleet comprising a whole number of reactors. In this regard, the mixed fleet of 38 reactors at the end of the transition scenarios of the French fleet which was previously published (Martin et al., 2016) can be considered symbiotic, with $x=0.2632 \approx 0.2547$. 


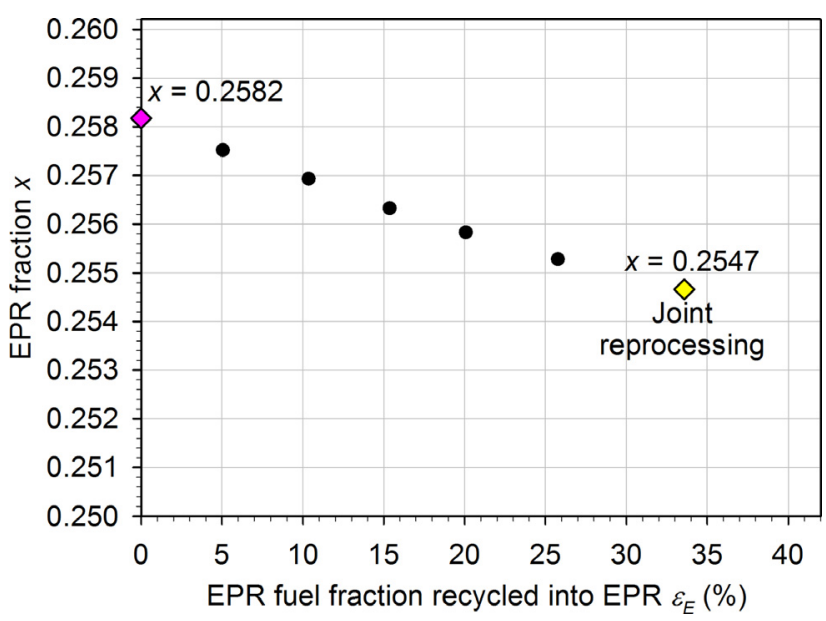

Fig. 10. Symbiotic equilibrium as a function of the spent fuel fraction $\epsilon_{E}$ selfrecycled into $\mathrm{EPR}^{\mathrm{TM}}$.

Table 3

Solutions corresponding to the highest $x$ value with distinct reprocessing and to joint reprocessing of spent fuels.

\begin{tabular}{lll}
\hline Variable & Main results & \\
\cline { 2 - 3 } & Distinct reprocessing & Joint reprocessing \\
\hline$x$ & 0.2582 & 0.2547 \\
$G_{E}^{*}$ & $65.84 \%$ & $G=63.36 \%$ \\
$G_{S}^{*}$ & $62.43 \%$ & \\
$\epsilon_{E}$ & 0 & 0.336 \\
$\epsilon_{S}$ & 0.605 & $\left(1-\epsilon_{E}\right)=0.664$ \\
\hline
\end{tabular}

The slight increase of $x$ when distinct reprocessing applies cannot be attributed to a higher fissile $\mathrm{Pu}$ production in SFR as expected initially. Indeed, the mean plutonium grade in SFR new fuels $G_{S}^{*}$ is $62.43 \%$, implying lower total and fissile Pu productions with regard to joint reprocessing $(G=63.36 \%)$ according to Fig. 8. The production of fissile Pu isotopes in SFR would only be improved for Pu grades lower than $60 \%$, which would require more $\mathrm{EPR}^{\mathrm{TM}}$ in the fleet.

To explain this $x$ difference, one has to consider the fissile $\mathrm{Pu}$ consumption in $\mathrm{EPR}^{\mathrm{TM}}$. The net consumption of fissile plutonium isotopes in an EPR ${ }^{\mathrm{TM}}$ can be estimated by $g N_{E}(g)-P_{E}(g) \Gamma_{E}(g)$. It decreases from $0.654 \mathrm{tHM} / \mathrm{yr}$ to $0.637 \mathrm{tHM} / \mathrm{yr}$ when $G_{E}^{*}$ rises from $63.36 \%$ (joint reprocessing) to $65.84 \%$ (distinct reprocessing). This effect is nonetheless an extrapolation since $65.84 \%$ lies outside the range of values covered by the EPR ${ }^{\mathrm{TM}}$ dataset (see dots in Fig. 5.a, b and $\mathrm{c}$ ). This is why the solutions presented in Table 3 have further been assessed through additional COSI6 simulations.

\section{COSI6 simulation}

The symbiotic equilibriums reported in Table 3 have been simulated using COSI6 (Coquelet-Pascal et al., 2015). In addition, mixed fleets of same composition as those previously studied (see Section 2) have been simulated. Reprocessing has been modeled as in the most recent scenarios built in collaboration with the French industry (Chabert et al., 2015; Tiphine et al., 2015; Martin et al., 2016). Besides, since it appeared impossible to model in practice precise reactor fractions using whole numbers of reactors, power plants have been modeled as parts of a single reactor unit. This amounts to considering, for instance, that the fuel stream through $x \mathrm{EPR}^{\mathrm{TM}}$ equal $x$ times that of a reactor of $1.6 \mathrm{GWe}$. Ten reactors have been operated in total $\left(10 \times x \mathrm{EPR}^{\mathrm{TM}}\right.$ and

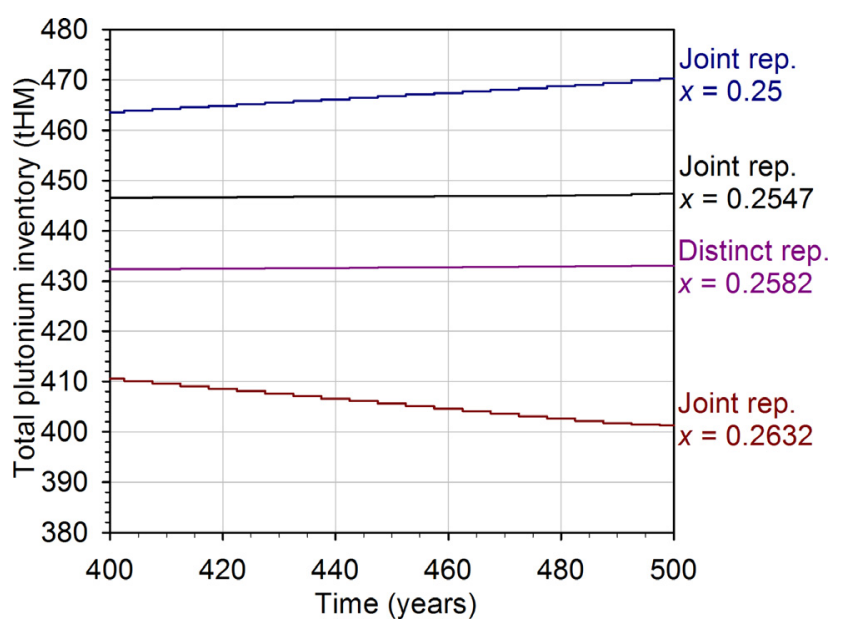

Fig. 11. Evolution for 100 years of plutonium inventories during COSI6 simulation of mixed $\mathrm{EPR}^{\mathrm{TM}}$ - SFR fleets (10 reactors).

$10 \times(1-x)$ SFR $).$ All the fractional reactors start within a same 5-year period. A Pu stock of around 500 tHM initially supplies MOX fuel fabrication plants when no spent fuel is still available. Poor and reprocessed uranium stocks are also withdrawn to make fertile and fissile fuels respectively. The simulations cover 500 years to ensure that a steady-state is reached. The total $\mathrm{Pu}$ inventories over the last 100 years of simulation are reported in Fig. 11.

A fairly stable plutonium inventory is obtained from the $x$ values representative of joint reprocessing (0.2547) and distinct reprocessing of spent fuels $(0.2582)$. However one can observe that the plutonium stock grows slowly. The low deviation from symbiotic equilibrium can be attributed to the slight difference between the applied linear regressions and the highest values of plutonium production (see Fig. 5). Indeed, the highest values of plutonium production mostly correspond to a minimum aging of plutonium close to 7 years, used to equate the symbiotic equilibrium with plutonium isotopic vectors collapsed into single scalar vectors (see Section 3.2). Nevertheless, linear regressions are not far from the highest values of Pu production and output grade data, especially for plutonium grades greater than $60 \%$ in SFR (see Fig. 5.e and $\mathrm{f}$ ). This explains why the deviation from a perfect Pu balance remains marginal.

These COSI6 simulations eventually assess the results obtained relatively to symbiotic equilibriums and further support that there is no significant difference in equilibrium fleet compositions for both reprocessing strategies. Therefore the more flexible joint reprocessing certainly constitutes a preferable option for the studied symbiotic nuclear system, composed of EPR ${ }^{\mathrm{TM}}$ and SFR.

\section{Conclusion}

The symbiotic equilibrium of a mixed fleet of $1.6 \mathrm{GWe} \mathrm{EPR}^{\mathrm{TM}}$ and 1.51 GWe breeder SFR is studied. EPR ${ }^{\mathrm{TM}}$ are fueled with MOX only: a symbiotic equilibrium indeed consists in a balance between the consumption and the production of fissile elements without any supply of natural resources when all irradiated fuels are reprocessed. The problem is tackled considering few simplifying assumptions:

- Only plutonium is assumed to impact the symbiotic equilibrium.

- A single real number, referred to as the Pu grade (see Eq. (2)), is supposed to account for the plutonium isotopic composition. 
- At least 7 years elapse between a spent fuel unloading operation and the in pile reintroduction of the Pu that it contains. A 7-year decay of ${ }^{241} \mathrm{Pu}$ is applied as regards this minimal $\mathrm{Pu}$ aging, which optimizes plutonium management at equilibrium.

- The plutonium need, production and grade evolution which characterize both irradiation sequences in $\mathrm{EPR}^{\mathrm{TM}}$ and SFR are reduced to linear functions upon the $\mathrm{Pu}$ grade in new fuels. These functions have been determined from the results of a previous scenario study (Martin et al., 2016) carried out with COSI6 (Coquelet-Pascal et al., 2015).

Two different reprocessing strategies are considered. With joint reprocessing of all spent fuels, only a single $\mathrm{EPR}^{\mathrm{TM}}$ fraction $x=0.2547$ in the fleet can balance total and fissile plutonium flows (symbiotic equilibrium). As expected from a former study (Martin et al., 2016), this $x$ value lies well between 0.25 and 0.2632 . When the plutonium from EPR ${ }^{\mathrm{TM}}$ spent fuels supplies SFR in priority (distinct reprocessing), $x$ may slightly increase up to 0.2582 . This increase is mainly due to a lower net plutonium consumption in $\mathrm{EPR}^{\mathrm{TM}}$ as the Pu grade in new fuels gets better. SFR breeding performance does not improve in that case.

Additional COSI6 simulations have been carried out to further assess the symbiotic equilibriums which have been found. One can therefore conclude that the EPR ${ }^{\mathrm{TM}}$ fractions in the fleet barely stand apart at symbiotic equilibrium whatever the reprocessing strategy, since they should correspond to the same fleet composition in practice (applying whole numbers of reactors). In this respect the more flexible joint reprocessing of spent fuels no doubt constitutes the reference option for the studied nuclear system.

\section{Acknowledgments}

The authors are grateful to AREVA and EDF for their support to this work through the ACF research program. In addition, they thank the members of the working group on "Industrial Scenarios" to have inspired this study.

\section{References}

Baker, A.R., Ross, R.W., 1963. Comparison of the value of plutonium and uranium isotopes in fast reactors. In: Proceedings of the conference on breeding, economics and safety in large fast reactors. Paper ANL 6792.

Buiron, L., Dujcikova, L., 2015. Low void effect (CFV) core concept flexibility: from self-breeder to burner core. In: Proceedings of ICAPP Paper 15091.

Chabert, C., Tiphine, M., Krivtchik, G., Allou, A., Saturnin, A., Girotto, J., Sarrat, P., Hancok, H., Mathonnière, G., Gabriel, S., Baschwitz, A., Fillastre, E., Giffard, F., Jasserand, F., Boullis, B., Leudet, A., Caron-Charles, M., Senentz, G., Carlier, B., Durpel, L.V.D., R.Grosman, Werf, J.V.D., Laugier, F., Settimo, D., Garzenne, C., 2015. Considerations on industrial feasibility of scenarios with the progressive deployment of Pu multi recycling in SFRs in the French nuclear power fleet. In: Proceedings of Global Paper 5351.

Chersola, D., Lomonaco, G., Marotta, R., 2015. The VHTR and GFR and their use in innovative symbiotic fuel cycles. Prog. Nucl. Energy 83, 443-449.

Coquelet-Pascal, C. Tiphine, M., Krivtchik, G., Freynet, D., Cany, C., Eschbach, R. Chabert, C., 2015. COSI6: a tool for nuclear transition scenarios studies and application to SFR deployment scenarios with minor actinides transmutation. Nucl. Tech. 192, 91-110.

Gao, F., Ko, W.I., 2014. Modeling and system analysis of fuel cycles for nuclear power sustainability (I): uranium consumption and waste generation. Ann. Nucl. Energy 65, 10-23.

Krivtchik, G., 2014. Analysis of Uncertainty Propagation in Nuclear Fuel Cycle Scenarios (Ph. D. thesis). Université de Grenoble.

Lasdon, L.S., Waren, A.D., 1983. Large scale nonlinear programming. Comput. Chem. Eng. 7, 159.

Lindley, B.A., Franceschini, F., Parks, G.T., 2014. The closed thorium-transuranic fue cycle in reduced-moderation PWRs and BWRs. Ann. Nucl. Energy 63, 241-254.

Martin, G., Girieud, R., 2016. Middle-term thorium strategy for PWR fleets. Energy Policy 99, 147-153.

Martin, G., Tiphine, M., Coquelet-Pascal, C., 2016. French transition scenarios toward a symbiotic nuclear fleet. In: Proceedings of ICAPP Paper 15732.

Tiphine, M., Coquelet-Pascal, C., Krivtchik, G., Eschbach, R., Chabert, C., Carlier, B. Caron-Charles, M., Senentz, G., Durpel, L.V.D., Garzenne, C., Laugier, F., 2015. Simulations of progressive potential scenarios of Pu multirecycling in SFR and associated phase-out in the French nuclear power fleet. In: Proceedings of Global Paper 5326.

Vidal, J.M., Eschbach, R., Launay, A., Binet, C., Thro, J.F., 2012. CESAR5.3: An industrial tool for nuclear fuel and waste characterization with associated qualification. In: Proceedings of the WM2012 conference, Phoenix, USA. 